\title{
Emergency Continuous Peritoneal Dialysis using Flexible Tenckhoff Catheter inserted with Reinforced Purse String Suture : An efficient substitute of renal replacement therapy in Critically Ill Patients with AKI when Intermittent Hemodialysis, Sustained low Efficiency Dialysis or Continuous Renal Replacement Therapy is not feasible
}

Sarwar Iqbal ${ }^{1}$, Tufayel Ahmed Chowdhury ${ }^{2}$, Mohammad Omar Faruq ${ }^{3}$, ASM Manzur Morshed Bhuiyan 4 , Mehruba Alam Ananna ${ }^{5}$, Muhammad Abdur Rahim ${ }^{6}$, Tabassum Samad ${ }^{7}$, Wasim Md. Mohosinul Haque ${ }^{8}$, ASM Areef Ahsan ${ }^{9}$, Fatema Ahmed ${ }^{10}$, Kaniz Fatema ${ }^{11}$

\begin{abstract}
Introduction : Renal replacement therapy (RRT) is often used to treat critically ill patients associated with acute or chronic renal failure. Peritoneal dialysis (PD) is an option when intermittent hemodialysis (IHD), sustained low efficiency dialysis (SLED) or Continuous renal replacement therapy (CRRT) are not feasible. PD customarily uses rigid catheter and cannot be used for more than 3 days as there is increased chance of infection and it can cause perforation of hollow viscera and often there is hemorrhage due to trauma to the adjacent organs. In this study we used Tenckhoffflexible PD catheter with double cuff and reinforced purse string suture ${ }^{l}$, So it can be used on an emergency basis and for indefinite period with minimal chances of complications commonly associated with rigid PD catheter. In this observational study emergency CPD using the procedure mentioned above in a compromised group of renal insufficiency patients was explored.
\end{abstract}

Objectives : To determine if emergency RRT can be achieved by CPD using flexible Tenckhoff catheter placed with special reinforced sutures when IHD, SLED or CRRT is not feasible in critically ill patients.

Material and Methods : Patients who failed to tolerate IHD, SLED or CRRT because of resulting hemodynamic instability and those who required dialysis urgently and for a prolonged period in Intensive Care Unit (ICU) were selected. There were 58 study cases who received emergency CPD after fulfilling inclusion criteria using flexible Tenckhoff catheter placed with special reinforced suture. These patients were on various life-support modalities having multiple co-morbidities. Regular exchanges were started manually with small volume on the day or the next day of catheter implantation, initially with 0.5-1 liter/session and subsequently with 2 liters per session after 15 days. Serum creatinine of study subjects were followed for 45 days and study subjects were followed for up to a year to check for survivability.

Results : In 58 critically ill cases that fulfilled the criteria were included in the study. Average age was $67.05 \pm 14.43$ years and 66\% were male. Majority were diabetic 48 (82.75\%) and the cause of AKI were sepsis in 39 cases (67.2\%) acute cardiovascular insufficiency in 9 cases (AMI \& NSTEMI 15.5\%), gastroenteritis in 3 cases (5.2\%), stroke in 4 cases (6.9\%) and multi organ failure in 7 cases (12.1\%). Average creatinine at the initiation of dialysis was $7.68 \pm 3.15$ and after 5 days it was 5.86 2.8, after 10 days $4.08 \pm 2.61$, after 15 days $2.87 \pm 2.1$, one month $2.32 \pm 1.90$ and after one and $a$ half months $2.31 \pm 1.88$. Volume overload was the indication of CPD in 22 (37.93\%) patients but main indication was uremia in $36(62.06 \%)$ cases. In ICU $23(39.7 \%)$ patients expired within a short (within 7 days) period. In the remaining 30(42.9\%) survived beyond 4 weeks (51.7); 22 (37.9\%) beyond 12 weeks; 14(24.1\%) beyond 24 weeks and 5(8.6)\% beyond 1 year. In 4 (2.32\%) patients PD catheter was removed as renal function improved. 35 patients were on mechanical ventilator and out of them 18 patients were weaned of mechanical ventilator (MV). $26 \mathrm{MV}$ patents (including weaned off) survived beyond 4 weeks. Mechanical complications from PD catheter in situ were very low and there was catheter related infection only in two cases.

Conclusion : Emergency CPD can be an alternate mode of renal replacement therapy $(R R T)$ in critically ill patients where emergency IHD, SLED or CRRT are not feasible. It was accompanied with low risk of procedure related complications and well tolerated.

Key words : Intermittent Hemodialysis (IHD), Sustained Low Efficiency Dialysis (SLED), Continuous Renal Replacement Therapy (CRRT), Continuous Peritoneal Dialysis (CPD), Peritoneal Dialysis (PD), Acute Kidney Injury (AKI), End Stage Renal Disease (ESRD), Renal Replacement Therapy (RRT) 


\section{Introduction :}

Renal replacement therapy (RRT) is being widely used in intensive care unit. Diagnosing and managing critically ill patients with renal dysfunction is an important part in the management of critically ill. Acute kidney injury (AKI)) in the intensive care unit (ICU) is frequent, as a part of multiple organ dysfunction syndrome (MODS). These patients have various co-morbid conditions and are on various life-supportive modalities. Fluid overload (causing anasarca), electrolyte and acid-base disturbances and drugs may further injure their organ systems. RRT plays a significant role in ICU in the treatment of patients with renal failure, acute as well as chronic.

The most common causes of AKI in the ICU are sepsis, hypovolemia resulting in renal hypoperfusion, low cardiac output and drugs. Other common causes include hepatorenal syndrome, rhabdomyolysis, and urinary flow obstruction, trauma, surgery etc.

1. Dr. Sarwar Iqbal, MD (Nephrology), Associate Professor \& Head, Dept. of Nephrology, BIRDEM General Hospital, Dhaka, Bangladesh

2. Dr.Tufayel Ahmed Chowdhury, FCPS (Medicine), Registrar, Dept. of Nephrology, BIRDEM General Hospital, Dhaka, Bangladesh

3. Prof. Mohammad Omar Faruq, MD, FACP, FACEP, FCPS, FCCM, Professor of Critical Care Medicine, Ibn Sina Hospital, Dhaka, Bangladesh.

4. Dr. ASM Manzur Morshed Bhuiyan, Senior Medical Officer, Dept. of Nephrology, BIRDEM General Hospital, Dhaka, Bangladesh

5. Dr. Mehruba Alam Ananna, FCPS (Medicine), Assistant Professor, Dept. of Nephrology, BIRDEM General Hospital, Dhaka, Bangladesh

6. Dr. Muhammad Abdur Rahim, FCPS (Medicine), Assistant Professor, Dept. of Nephrology, BIRDEM General Hospital, Dhaka, Bangladesh

7. Dr. Tabassum Samad, FCPS (Medicine), Junior Consultant, Dept. of Nephrology, BIRDEM General Hospital, Dhaka, Bangladesh

8. Dr.Wasim Md. Mohosinul Haque, FCPS (Medicine), Associate Professor, Dept. of Nephrology, BIRDEM General Hospital, Dhaka, Bangladesh

9. Dr. ASM Areef Ahsan, MD (Chest), FCPS (Medicine), MD (CCM), Associate Professor, Dept. of Critical Care Medicine, BIRDEM General Hospital, Dhaka, Bangladesh

10. Dr. Fatema Ahmed, FCPS (Medicine), MD (CCM), Assistant Professor, Dept. of Critical Care Medicine, BIRDEM General Hospital, Dhaka, Bangladesh

11. Dr. Kaniz Fatema, FCPS (Medicine), MD (CCM), Assistant Professor, Dept. of Critical Care Medicine, BIRDEM General Hospital, Dhaka, Bangladesh

\section{Corresponding Author :}

Dr. Sarwar Iqbal,

MD (Nephrology)

Associate Professor \& Head

Dept. of Nephrology

BIRDEM General Hospital, Dhaka 1000, Bangladesh.

E mail: sarwariqbal2003@yahoo.com
The common modes of RRT include, Intermittent Hemodialysis (IHD), Continuous RRT (CRRT), Slow low-efficiency dialysis (SLED) and Peritoneal dialysis (PD). Peritoneal dialysis is again of two types. Acute Peritoneal Dialysis (APD) / Intermittent Peritoneal Dialysis (IPD) using Rigid Catheter and Continuous Peritoneal Dialysis (CPD) using flexible catheter (Tenckhoff catheter).

In $70 \mathrm{~s}$ and $80 \mathrm{~s}, \mathrm{PD}$ was the leading modality of renal replacement therapy used in AKI patients ${ }^{2}$. At that time IHD and CRRT were not widely available for AKI in ICU. In the 70 s, acute PD using rigid catheter was widely accepted for AKI treatment, but its practice gradually declined in favor of hemodialysis, as it began to be widely available ${ }^{3-6}$. PD is still frequently used in developing countries because of its lower cost and minimal infrastructural requirements ${ }^{4,5}$. It is also widely used to treat ESRD in developing countries like Bangladesh in the recent past because of its low cost. Recently, interest in using PD to manage AKI patients has been increasing be because it is now believed that PD can provide adequate metabolic and fluid control for treating AKI patients. One important issue of using PD in AKI is that the chances of recovery is faster in PD than HD as in PD the peritoneum acts as the natural biological membrane and the blood is not exposed to the bio-incompatible artificial membrane which is used in HD.

The field of RRT has undergone remarkable changes over the last decade and is continuing to evolve rapidly. CRRT is now firmly established throughout the world as perhaps the most commonly used form of RRT in hemodynamically unstable patients. CRRT is clearly superior to IHD with regard to physiological end points. Modifications of IHD, such as SLED, are able to combine the advantages of both IHD and CRRT. But there are situations when neither SLED nor CRRT is feasible because of hemodynamic instability which cannot be managed with inotropes. These are the cases where CPD is the only viable alternative modality of RRT. CPD is new concept in the management of renal failure in critically ill where other modalities like IHD, SLED and CRRT become unsuccessful.

Critical care nephrology is a fast-emerging subspecialty, and critical care physicians are likely to play a paramount role in the management of patients with renal failure.

The work by Gabriel et $\mathrm{al}^{7}$, showed that, with careful thought and planning, critically ill patients can be successfully treated by PD. To overcome some of the classic limitations of PD use in AKI, such as a high chance of infection and no metabolic control, they proposed the use of cycles, flexible catheter, and a high volume of dialysis fluid.

\section{Methodology :}

This prospective study was done in Bangladesh Institute of Research and Rehabilitation in Diabetes, Endocrine and Metabolic Disorders (BIRDEM) ICU between January 2010 and December 2015. Patients who developed Acute Kidney Injury (AKI) or Acute on Chronic Kidney Disease (CKD) requiring renal replacement therapy and those who could not 
tolerate IHD and SLED were selected for CPD in this study. Patients who had systolic blood pressure below $100 \mathrm{~mm}$ of $\mathrm{Hg}$ with inotropes were included assuming they will not sustain IHD, SLED or CRRT if at all started. Patients suffering from ESRD and patients with recent abdominal surgery were excluded.

The objective of this study was to see whether emergency RRT is feasible with CPD using flexible Tenckhoff catheter in critically ill patients when IHD, SLED or CRRT is not practicable.

AKI is defined according to RIFLE (Risk, Injury, Failure, Loss and End - stage disease) criteria proposed by the Acute Dialysis Quality Initiative (ADQI) group ${ }^{8}$.

In all cases straight Tenckhoff catheter (Fig 1) was implanted by mini laparotomy with purse string suture (Fig 2) so that the catheter is in stable position and there is no chance of fluid leakage. A double turn of reinforced suture was also used to make it further leakage proof. The PD catheter was further fixed in an oblique fashion so that the tip of the catheter remains in the pelvis and does not migrate into the upper abdomen. The purse string suture is placed between parietal peritoneum and lower Dacron cuff of the PD catheter (Fig 3). This new method was first introduced by Iqbal et $\mathrm{al}^{1}$. Inj. Vancomycin $500 \mathrm{mg}$ and Inj. Amikacin $100 \mathrm{mg}$ was used into peritoneal cavity as prophylactic antibiotic one time only during the procedure.

There are different methods of Tenckhoff catheter implantation e.g. per cutaneous puncture and peel off method or laparoscopic implantation. In conventional method of catheter implantation it takes 2 weeks to start regular exchanges. It takes 2 weeks for the Dacron cuffs on the catheter to adhere with the tissue hoping that it will prevent fluid leakage. The advantage of method used in our study was that regular exchanges could be started on the day or on the day after catheter implantation.

In all cases regular exchanges of fluid was started on the same day or on the following day with small volume i.e. $1000 \mathrm{ml}$ with a dwell time of 4 hours (total 6.0L a day). Fluid used was $1.5 \%, 2.5 \%$ and $4.25 \%$ glucose solution.

For the analysis of technique survival, the primary event was defined as switch over to hemodialysis for any reason, which means the patient could not continue PD until the end of the follow up.

The study was approved by instructional review board of BIRDEM hospital and informed written consents were taken from study subjects' legal guardians.

Statistical Package for the Social Sciences (SPSS) version 20.0 was used to analyze data. Quantitative data were analyzed by mean and standard deviation from the mean and qualitative data were expressed as frequency with corresponding percentage.

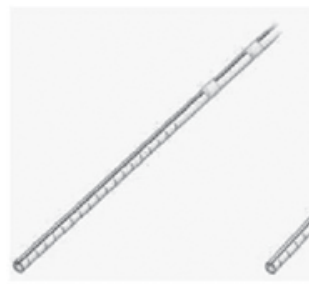

Straight

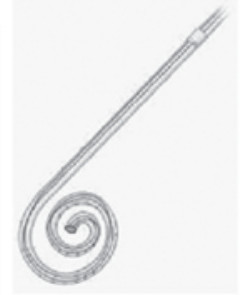

(used in the study)

\section{Coiled}

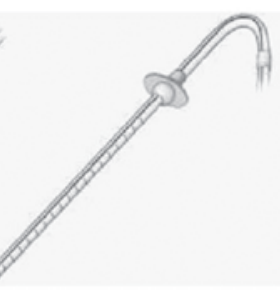

Fig 1 : Varities of Tenckhoff Catheter (courtesy Google image)

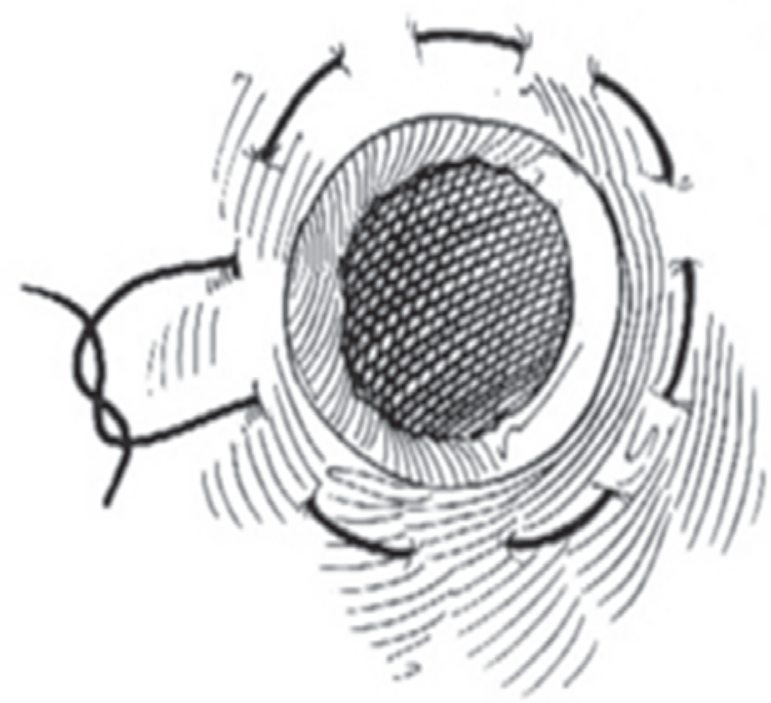

Fig 2: Purse String Suture (courtesy Google image)

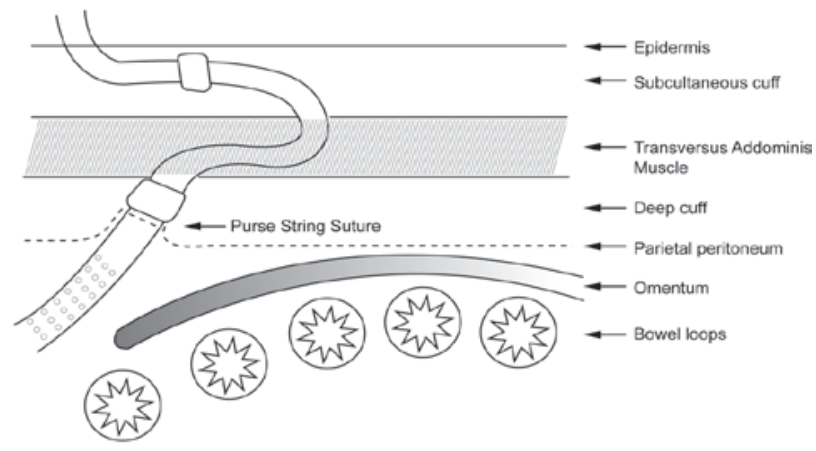

Fig 3: Catheter as implanted in peritoneal cavity

\section{Results :}

Out of 58 cases $23(39.7 \%)$ patient were more than 70 years of age. Age group distribution shown in Table 1. Among them 38 $(66 \%)$ were male and rest were female. 
Table 1

\begin{tabular}{lcc}
\hline Age & Number & Percentage \\
\hline$<40$ years & 02 & 03.4 \\
$41-50$ yrs & 07 & 12.1 \\
$51-60$ yrs & 12 & 20.7 \\
$61-70$ yrs & 14 & 24.1 \\
$71-80$ yrs & 11 & 19.0 \\
$>80$ yrs & 12 & 20.7 \\
Total & 58 & 100.0 \\
Mean \pm SD & $67.05( \pm 14.43)$ & Range $39-90$ years \\
\hline
\end{tabular}

Majority or the patients were diabetic 48 (82.75\%). Among study population sepsis comprised major bulk of co morbidities followed by acute cardiovascular insufficiency. (Table 2). There were multiple overlaps among the co morbidities.

Table 2

\begin{tabular}{lcc}
\hline Co morbidities & Number & Parentage \\
\hline Sepsis & 39 & 67.2 \\
Acute cardiovascular insufficiency & 09 & 15.5 \\
Gastroenteritis & 03 & 5.2 \\
Stroke & 04 & 6.9 \\
Multi organ failure & 07 & 12.1 \\
\hline
\end{tabular}

Initial average serum creatinine at the start of CPD was 7.68 $( \pm 3.15)$ and gradually declined thereafter.( Table 3$)$.

Table 3

\begin{tabular}{lcc}
\hline $\begin{array}{l}\mathbf{N}=\text { Number of patients, whose } \\
\text { s.creatinine was tested }\end{array}$ & $\begin{array}{c}\text { Mean } \pm \text { SD } \\
\mathbf{m g} / \mathbf{d l}\end{array}$ & $\begin{array}{c}\text { Range (Minimum } \\
\text {-maximum) } \mathbf{m g} / \mathbf{d l} \backslash\end{array}$ \\
\hline Creatinine at initiation $(\mathrm{N}=58)$ & $7.68( \pm 3.15)$ & $3-15$ \\
Creatinine after 5 days $(\mathrm{N}=51)$ & $5.87( \pm 2.80)$ & $2-13$ \\
Creatinine after 10 days $(\mathrm{N}=42)$ & $4.08( \pm 2.61)$ & $1-11$ \\
Creatinine after 15 days $(\mathrm{N}=29)$ & $2.87( \pm 2.11)$ & $1-9$ \\
Creatinine after 30 days $(\mathrm{N}=15)$ & $2.32( \pm 1.90)$ & $1-8$ \\
Creatinine after 45 days $(\mathrm{N}=12)$ & $2.31( \pm 1.88)$ & $1-8$ \\
\hline
\end{tabular}

Twenty two patients (37.9\%) received CPD for fluid overload resulting in anasarca. As Icodextrine (has better out come in anasarca patients) is not available in Bangladesh it could not be used in patients with fluid overload in our study.

Twenty-three patients (39.7\%) expired at ICU in less than 7 days. All subjects who survived were followed beyond one year when transferred out of ICU or after being discharged from the hospital (Table 4).
Table 4

\begin{tabular}{lcc}
\hline Survived & Number & Percentage \\
\hline Survived Beyond 4 weeks & 30 & 51.7 \\
Survived Beyond 12 weeks & 22 & 37.9 \\
Survived Beyond 24 weeks & 14 & 24.1 \\
Survived Beyond 1 Years & 5 & 8.6 \\
\hline
\end{tabular}

In this study $35(60.3 \%)$ patients were on mechanical ventilation from the time of catheter implantation. Of those cases, 26 patients survived beyond 4 weeks and 18 cases were successfully weaned off ventilation. Small volume of high glucose containing ( 2.5 to $4.25 \%$ ) intra-peritoneal fluid was used in patients on MV (1 liter per session) and resulting increased intra abdominal pressure did not significantly affect weaning from MV.

In our study, there were no mechanical complications like leakage of PD fluid, catheter tip migration, catheter blockage or kinking of catheter.

Out of 58 cases in our study, in one case there was peritonitis associated with $\mathrm{E}$ coli infection. It was resolved with intra-peritoneal antibiotics. In the other case there was growth of Pseudomonas along with Candida in the peritoneal fluid. In this case the catheter was removed and the patient was switched back to SLED.

\section{Discussion :}

There is no credible study found in literature describing feasibility of emergency CPD in critically ill AKI patients as CPD unlike IPD using rigid PD catheter cannot be initiated on an emergency basis. Customarily it takes about 2 weeks for the Tenckhoff catheter to go into leak proof state when RRT can be initiated on an elective basis. Our study has introduced a new method to make the Tenckhoff Catheter useable on the first day or the second day of insertion thus making CPD an efficient alternative to emergency IHD, emergency SLED or CRRT, when needed for prolonged period and when these modalities are unsuitable in critically ill patients.

Literature describing experience of using conventional CPD usually involves AKI as well as ESRD patients. So no credible comparison can be made between our study and those reported in different literatures.

The mean age in our study subjects was $67.05 \pm 14.43$ years and $66 \%$ were male. In study by Gabriel et $\mathrm{al}^{9}$ mean of age of the patients was $64.2 \pm 19.8$ years and $72 \%$ were male.

In our study, the cause of AKI were sepsis (67.2\%) acute cardiovascular insufficiency (AMI \& NSTEMI 15.5\%), gastroenteritis $(5.2 \%)$ stroke $(6.9 \%)$ and in rest multi organ failure (12.1\%). In one study by Ponce et $\mathrm{al}^{10}$. Sepsis was the main cause of AKI (53.2\%) followed by heart failure (26.9\%).

Volume overload was the indication of dialysis in only 22 $(37.93 \%)$. Uremia or azotemia was the main indication for CPD in our study (62.1\%). This is similar to study by Ponce et $\mathrm{al}^{10}$ where uremia or azotemia was the main indication for dialysis (63.1\%). 
In our study average creatinine at the initiation of dialysis was $7.68 \pm 3.15 \mathrm{mg} / \mathrm{dl}$ and after 5 days it was $5.87 \pm 2.80 \mathrm{mg} / \mathrm{dl}$. One prospective study by Gabriel et $\mathrm{al}^{6}$ on $30 \mathrm{AKI}$ patients showed that after 4 days of CPD, patients had stable BUN value $<50 \mathrm{mg} / \mathrm{dl}$ and creatinine $<4 \mathrm{mg} / \mathrm{dl}$.

In our study $39.7 \%$ expired within a week $51.7 \%$ survived beyond 4 weeks. But in study by Ponce et $\mathrm{al}^{10}$ mortality rate was $59.8 \%$ in one month follow up.

Despite all efforts, mortality rates as per different studies remain extremely high in RRT of AKI patients ${ }^{11-16}$. In line with previous reports, the mortality of AKI patients undergoing different methods of RRT ranged from $40-80 \%$, according to etiology and severity of AKI patients ${ }^{12,16}$.

However earlier studies have shown that patients treated with PD had lower mortality rates and a higher incidence of renal recovery than did similar patients treated with HD alone ${ }^{17,18}$.

In our study only two patients out of 58 developed peritonitis (one case showed E coli and the other showed Pseudomonas and Candida). But in study by Gabriel et ${ }^{9}$ rate of peritonitis was 18 percent and 7\% required catheter removal. In addition RRT method was changed because of lack of improvement in laboratory parameters after 5 days of specific treatment for peritonitis. Pseudomonas aeruginosa, Staphylococcus aureus and Fungi were the main causative organisms in that study.

In our study $35(60.3 \%)$ cases were on mechanical ventilation, among them 18 cases were weaned off. However no credible study regarding effects of $\mathrm{PD}$ on mechanical ventilation has been widely reported. In one study on AKI treated by IPD, done by Almeida et al $^{19}$ showed that hypoxemia did not worsen and $\mathrm{PaO}_{2} / \mathrm{FiO}_{2}$ improved progressively with $\mathrm{PD}$.

In our study, there were no mechanical complications like leakage of peritoneal fluid or catheter tip migration or blockage of catheter because of this new method ${ }^{1}$ of catheter implantation. But in the study by Ponce et $\mathrm{al}^{10} 14.6 \%$ patients developed mechanical complications. Leakage of peritoneal fluid and catheter tip migration were the majority of the complications $(79.5 \%)$, with therapy being interrupted in $54.5 \%$ patients in that study.

The significant limitation in our study is the small number of study cases done only in one center. A multicenter study involving much larger study subjects would be credible. Besides we did not address the length of ICU stay of the study subjects to see if it was influenced by emergency CPD. Future similar study must consider length of ICU stay to see if emergency CPD positively influences outcome of study population. Among other limitations, it is worth mentioning that our study did not compare outcome between subjects suffering from AKI and subjects suffering from AKI on CKD. It would be interesting to know if there is any difference in outcome between this two groups.

\section{Conclusion :}

Peritoneal dialysis remains an effective therapy which is simple and easy to use. Historically, PD has been used with success for the treatment of AKI. Continuous Peritoneal dialysis (CPD) can be the ultimate hope of RRT in severely critically ill patients where IHD, SLED or CRRT is not feasible. With our newly developed technique, CPD can be started on emergency basis and may be continued for indefinite period without any technical complications like fluid leakage, catheter tip migration and infection. and it appeared well tolerated. Poorer outcomes are likely to be dependent on underlying co-morbidities and older age.

\section{References :}

1. Iqbal S, Islam N, Mansur MA, Ahmed Z. Purse-string suture facilitates early start of dialysis and prevents catheter tip migration. $3^{\text {rd }}$ Asian Chapter Meeting of International Society of Peritoneal Dialysis, 22 - 24 November 2007, Hiroshima, Japan.

2. Steiner RW. Continuous equilibration peritoneal dialysis in acute renal failure. Perit Dial Int. 9: 5-7, 1989

3. Uchino S, Kellum JA, Bellomo R, Doig GS, Morimatsu H, Morgera S, et al, Beginning and Ending Supportive Therapy for the Kidney (BEST Kidney) Investigators: Acute renal failure in critically ill patients: A multinational, multicenter study. JAMA 294: 813-818, 2005

4. Ricci Z, Ronco C, D'Amico G, De Felice R, Rossi S, Bolgan I, et al. Practice patterns in the management of acute renal failure in the critically ill patient: An international survey. Nephrol Dial Transplant 2006;21:690-696

5. Sugino N, Kubo K, Nakazato. Therapeutic Modalities and Outcome in Acute Renal Failure: Acute Renal Failure, New York, Marcel Dekker, 1992, pp443-454.

6. Gabriel DP, Nascimento GV, Caramori JT, Martim LC, Barretti P, Balbi AL. Peritoneal dialysis in acute renal failure. Ren Fail 2006; 28: 451-456.

7. Gabriel DP, Nascimento GV,Caramori JT, Martim LC, Barretti P, Balbi AL. High volume peritoneal dialysis for acute renal failure. Perit Dial Int2007; 27: 277-282.

8. Bellomo R, Ronco C, Kellum JA, Mehta RL, Palevsky P. Acute Dialysis Quality Initiate work group. Acute Renal Failuredefinition, outcome measures, animal models, fluid therapy and information technology: the second International consensus conference of the Acute Dialysis Quality Initiative (ADQI) Group. Crit care 2004; 8(4): R 204-12.

9. Gabriel DP, Caramori JT, Martin LC, Barretti P, Balbi AL. Continuous peritoneal dialysis compared with daily hemodialysis in patients with acute kidney injury. Perit Dial Int. 2009 Feb; 29 Suppl 2:S62-71.

10. Ponce D, Buffarah MB, Goes C, Balbi A. Peritoneal Dialysis in Acute Kidney Injury: Trends in the Outcome across Time Periods. 2015 PLoS ONE 10(5): e0126436. doi: 10.1371/journal.pone.0126436

11. Levy MM, Macias WL, Vincent J-L, Russell JA, Silva E, Trzaskoma B, et al. Early changes in organ function predict eventual survival in severe sepsis. Crit Care Med. 2005; 33(10):2194-201.

12. Uchino S, Kellum JA, Bellomo R, Doig GS, Morimatsu H, Morgera $\mathrm{S}$, et al. Acute renal failure in critically ill patients: a multinational, multicenter study. JAMA. 17 de Agosto De 2005;294(7):813-8.

13. Ricci Z, Ronco C, D'Amico G, De Felice R, Rossi S, Bolgan I, et al. Practice patterns in the management of acute renal failure in the critically ill patient: an international survey. Nephrol Dial Transplant 2006; 21(3):690-6. 
14. Chionh CY, Soni SS, Finkelstein FO, Ronco C, Cruz DN. Use of peritoneal dialysis in AKI: a systematic review. Clin J Am Soc Nephrol. 2013; 8(10):1649-60. doi: 10.2215/CJN.01540213

15. Cullis B, Abdelraheem M, Abrahams G, Balbi A, Cruz DN, Frishberg Y, et al. Peritoneal dialysis for acute kidney injury. Perit Dial Int 2014;34(5):494-517.

16. Waikar SS, Curhan GC, Wald R, McCarthy EP, Chertow GM Declining mortality in patients with acute renal failure, 1988 to 2002. J Am Soc Nephrol 2006;17(4):1143-50.

17. Kjellstrand CM, Solez K. Treatment of acute renal failure. In: Schrier WR, Gottschalk WC, editors. Diseases of the Kidney. 5th edition. Vol. 2. Boston, Mass, USA: Little, Brown and Company; 1993. pp. $1385-1394$.
18. Swartz RD, Valk TW, Brain AJS, Hsu CH. Complications of hemodialysis and peritoneal dialysis in acute renal failure. ASAIO Journal. 1980; 3(3):98-101.

19. Almeida CP, Ponce D, de Marchi AC, Balbi AL. Effect of peritoneal dialysis on respiratory mechanics in acute kidney injury patients. Perit Dial Int. 2014 Jul-Aug; 34(5):544-9. 